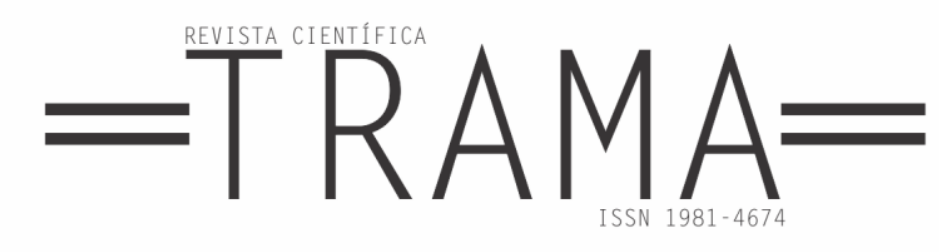

\title{
A luta do movimento Surdo Pelo direito À língua
}

\author{
Tamara Cardoso ANDRÉ1 \\ Andréa Carolina Bernal MAZACOTTE ${ }^{2}$
}

\begin{abstract}
Resumo: Escrito em coautoria entre uma professora surda e uma professora ouvinte, tem o objetivo de relatar as conquistas do Movimento Surdo em Foz do Iguaçu. Discute leis federais e documentos oficiais do Ministério da Educação (MEC) e da Secretaria do Estado da Educação do Paraná sobre direito à educação e à Língua Brasileira de Sinais. Conclui que o Movimento Surdo não apenas precisou lutar para aprovar leis que afirmassem o direito ao uso da língua de sinais, como também lutar para a efetivação destas leis. Por isso, a luta do Movimento Surdo é permanente e precisa estar viva em cada município e em cada instituição, tendo em vista a importância que tem a Língua de Sinais para o desenvolvimento global da pessoa surda.
\end{abstract}

Palavras-chave: Língua Brasileira de Sinais, Direitos Linguísticos, Movimento Surdo.

\begin{abstract}
Written in co-authorship by a deaf teacher and a hearing teacher, it aims to present the achievements of the Deaf Movement in Foz do Iguaçu. It discusses federal laws and official documents of the Ministry of Education (MEC) and the Board of Education of the Parana State about the right to education and to Brazilian Sign Language. It concludes that the Deaf Movement not only had to struggle to approve laws which ensure the right to signal language, but also had to struggle to make sure those laws were effective. For this reason, the struggle of the Deaf Movement is permanent and needs to be alive in each municipality and in each institution, considering the importance of the sign language for the global development of the deaf person.
\end{abstract}

Keywords: Deaf Movement, Bilingualism, Brazilian Sign Language.

\footnotetext{
${ }^{1}$ Pedagoga, Doutora em Educação. Professora da Universidade Estadual do Oeste do Paraná, Campus Foz do Iguaçu. E-mail: tamaracardosoandrefoz@gmail.com

${ }^{2}$ Mestranda no Programa de Pós-graduação Stricto Sensu em Ensino (PPGEn), Universidade Estadual do Oeste do Paraná (UNIOESTE) - Campus Foz do Iguaçu. andreamztunioeste@ gmail.com
} 


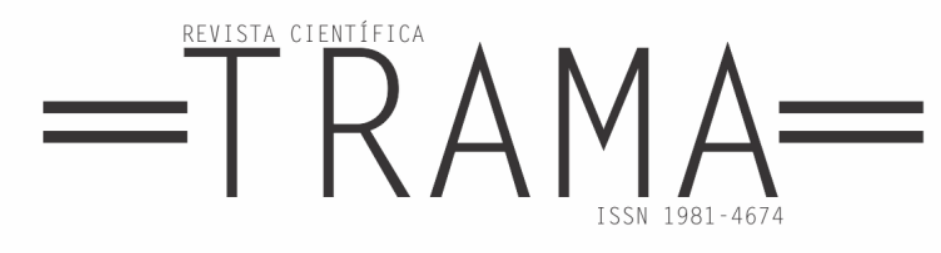

\section{$\mathbf{I}_{\text {NTRODUÇão }}$}

O objetivo deste artigo, escrito em coautoria entre professora surda e professora ouvinte, é apresentar relato sobre as conquistas do movimento surdo em Foz do Iguaçu pelo direito à língua de sinais, relacionando com o Movimento Surdo no Brasil.

Uma conquista importante dos surdos foi o acesso à educação e também ao ensino superior, ainda mais ampliada com a proposta do ENEM em Língua Brasileira de Sinais $^{3}$ (Libras), a partir de 2017. O Exame Nacional do Ensino Médio (ENEM) é uma prova nacional que avalia os alunos do ensino médio e pode ser usada para ingresso no ensino superior. Mas todo avanço é resultado da luta da comunidade surda para ter sua língua reconhecida.

\section{A educação de surdos e a LÍNGUA DE SINAIS}

No ano de 1996 foi publicada a "Declaração Universal dos Direitos Linguísticos", pela Organização das Nações Unidas para a Educação, a Ciência e a Cultura (UNESCO, 1996). O documento afirma o direito de aprendizagem, uso e disseminação de todas as línguas, o que inclui as línguas de sinais. Trata-se de fundamental conquista para os surdos, outrora proibidos de usar a língua de sinais, dada a importância desta para as interações e desenvolvimento cultural.

De acordo com Quadros e Cruz (2011), a aquisição da linguagem, para qualquer criança, ocorre naturalmente nas situações de interação. No caso das crianças surdas, a aquisição da língua de sinais é natural se o meio assim oportunizar. Entretanto, Quadros e Schmiedt (2006) afirmam que cerca de $95 \%$ das crianças surdas são filhas de ouvintes que não dominam a língua de sinais. Assim, um importante problema que se coloca é oportunizar à criança surda o acesso à língua de sinais desde os primeiros meses de vida.

Segundo Svartholm (2014), o modelo bilíngue para a educação de pessoas surdas, originalmente adotado na Suécia, tem como princípio o acesso à língua de sinais desde o nascimento da criança surda, servindo de base para o ensino da segunda língua, na modalidade escrita. A leitura labial e a fala também são usadas como complemento à língua de sinais e à língua escrita. Svartholm (2014) afirma que na Suécia mais de $90 \%$ das crianças recebem implantes cocleares, mas, mesmo assim, necessitam da aprendizagem e do uso da língua de sinais, o que é oportunizado desde os primeiros meses de vida por meio da educação infantil, uma vez que se entende a importância do ensino da língua para o desenvolvimento integral da pessoa surda. $\mathrm{O}$ bilinguismo na educação de surdos, portanto, tem como premissa a importância da língua de sinais para o desenvolvimento da pessoa surda, em oposição aos métodos de ensino que visam o desenvolvimento da oralidade.

Honora (2014) explica que no século XVIII coexistiam o método de ensino por sinais; elaborado pelo francês L'Epée; e o oralismo; desenvolvido pelo alemão Heinicke. A partir do Congresso de Milão, em 1880, foi estabelecida a adoção do oralismo no mundo todo. Apenas um século depois o uso de sinais voltou ao cenário educativo, devido ao fracasso do oralismo, embora tenha ganhado força a partir da década de 1960, devido às tecnologias inventadas para rentar reparar o déficit auditivo, como os implantes cocleares. De acordo com Capovilla (2000), o objetivo do método oralista é o treino da fala, e não o ensino de conhecimentos gerais, o que atrasa o ensino da leitura, da escrita e das disciplinas escolares, podendo provocar déficit cognitivo.

O fracasso do oralismo, assim como a ineficiência dos implantes cocleares para parte das pessoas surdas, favoreceram a continuidade do uso da língua de sinais por pessoas surdas. Stokoe (1960), pesquisador

\footnotetext{
${ }^{3}$ Informações disponíveis em:

<encurtador.net/DKLR0>. Acesso em $10 \mathrm{dez}$.

2017.
} 


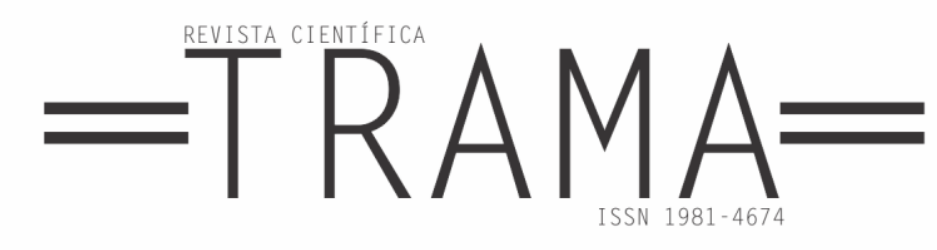

da Universidade Gallaudet, em Washington, desenvolveu uma série de estudos sobre as características da língua de sinais, o que acarretou na fundamentação da comunicação total, na década de 1970. Segundo Ciccone (1990), a comunicação total é uma pedagogia da educação de surdos que junta todas as formas de comunicação, incluindo língua de sinais, alfabeto manual, leitura labial, português sinalizado e oralismo. A comunicação total é praticamente contemporânea ao bilinguismo na educação de surdos. Segundo Svartholm (2009), o bilinguismo teve seu surgimento na Suécia a partir de pesquisas que detectaram naquele país a ineficácia de uso simultâneo da fala e de sinais para o ensino e o desenvolvimento das crianças surdas:

O marco do modelo bilíngue para o ensino comparado à educação dos surdos como foi anteriormente feito na Suécia, é basicamente o papel que ele atribui à língua de sinais. (SVARTHOLM, 2009, p. 18).

Segundo Svartholm (2009), alunos com acesso a uma educação consistentemente bilingue desenvolveram capacidade de leitura comparável aos estudantes ouvintes, conforme comprovam estudos realizados na Suécia, onde o modelo é adotado.

Honora (2014) afirma que no Modelo de Educação Bilingue da Suécia a Língua de Sinais é a primeira Língua (L1) e a língua oral do país é a Segunda Língua (L2), devendo ser adquirida pelo surdo na modalidade escrita. O surdo é ensinado em língua de sinais, por meio da qual adquire a escrita. O modelo de educação bilingue para surdos desenvolvido na Suécia passou a fundamentar a pedagogia para surdos no Brasil na década de 2000.

No Brasil a língua da comunidade surda é a Língua Brasileira de Sinais (Libras). Quadros e Schmiedt (2006) explicam que a Libras é uma língua visual-espacial e apresenta todos os elementos que caracterizam as línguas humanas. Os fonemas são as unidades mínimas da língua, da mesma forma que as configurações das mãos são as unidades mínimas das línguas de sinais. As expressões faciais cumprem a função da entonação na indicação daquilo que é representado por sinais de pontuação, como, por exemplo, a interrogação. Algumas configurações de mãos formam os classificadores da língua de sinais, ao serem usadas para indicar ações incorporadas aos objetos. Por exemplo, há um classificador para distinguir se a velocidade de determinada ação é rápida ou lenta. De acordo com Quadros e Cruz (2011), as línguas de sinais podem ser analisadas em seus aspectos linguísticos em todos os níveis das línguas orais: fonológico, morfológico, sintático, semântico e pragmático. O nível que nas línguas orais é fonológico, nas línguas de sinais é quirológico, conforme apontam os estudos de Stokoe (1960). Ou seja, do mesmo modo que o nível fonológico compreende as unidades mínimas de sons sem significados, o nível quirológico compreende as unidades mínimas de movimentos sem significados, sendo eles, conforme caracterização de Stokoe (1960): configuração de mão, movimento, locação e orientação de mão.

Entretanto, apesar da comprovada importância da língua de sinais, a comunidade surda necessita de constante luta para ter acesso à língua $\mathrm{e}$ à aprendizagem.

\section{A EDUCAÇÃo DE SURDOS E A LUTA DA COMUNIDADE SURDA NO BRASIL}

As investigações que comprovaram os aspectos linguísticos das línguas de sinais ajudaram a fundamentar a luta dos surdos pelo direito à língua de sinais.

Segundo Fernandes e Moreira (2014), na década de 1990 cresceram os movimentos surdos brasileiros, formados por pessoas surdas, seus familiares e acadêmicos. Estes movimentos buscaram defender a cultura surda, concebendo a surdez como diferença, e não como patologia. Um marco se deu em 1999, quando o Núcleo de Pesquisa em Políticas de Educação para Surdos (NUPPES), da Universidade Federal do Rio Grande do Sul (UFRGS), organizou o V Congresso Latino-Americano de Educação Bilíngue para Surdos, onde foi produzido um texto, elaborado junto à Federação Nacional 


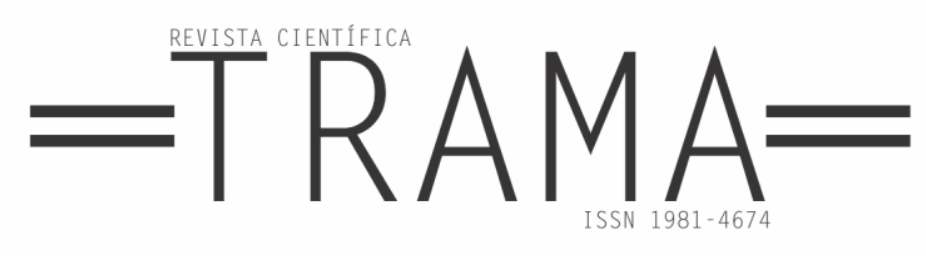

de Educação e Integração dos Surdos (FENEIS), sobre o que queria a comunidade surda. FENEIS é uma entidade filantrópica de defesa dos direitos das pessoas surdas, fundada em 1987.

O documento (FENEIS, 1999) pauta as políticas específicas para a educação de surdos com base no modelo bilíngue, requeridas pela comunidade surda. Reivindica o reconhecimento da língua de sinais na educação de surdos em todas as escolas, o direito ao acesso à língua de sinais e outras línguas pela criança surda, o acesso a todos os níveis de ensino e formação profissional, iniciativas visando impedir o preconceito contra surdos, legenda em língua de sinais na mídia televisiva, política pública de atendimento às crianças de rua surdas, não imposição do aparelho de audição aos surdos, presença de intérprete de língua de sinais e critérios específicos de avaliação para surdos prestarem concursos e exames vestibulares, incorporação de ensino de língua de sinais em cursos de ensino superior, dentre outras medidas visando a garantia de direitos aos surdos. Em relação à escolarização, o documento apresenta a seguinte reivindicação:

Propor o fim da política de inclusão/integração, pois ela trata o surdo como deficiente e, por outro lado, leva ao fechamento de escolas de surdos e/ou ao abandono do processo educacional pelo aluno surdo. (FENEIS, 1999).

Apesar de o documento datar de 1999, apenas no dia 24 de abril de 2002 foi aprovada no Brasil a Lei de Libras - Lei ${ }^{\circ}$ 10.436/2002. A Lei reconhece a Libras como forma de comunicação e expressão e sistema linguístico de natureza visualmotora com estrutura gramatical própria, oriundo de comunidades de pessoas surdas no Brasil. Em seguida, no ano 2015, o Decreto $\mathrm{n}^{\circ} 5.626$ torna obrigatório o ensino de Libras nos cursos de formação de professores para o exercício do magistério.

Entretanto, existem avanços e retrocessos na educação de surdos. Fernandes e Moreira (2014) afirmam que os documentos curriculares oficiais prejudicam a educação de surdos ao enfatizarem mais a inclusão do que a educação bilíngue. O sistema escolar brasileiro ainda não propicia aos surdos nem a aprendizagem plena da língua de sinais, nem da língua portuguesa na modalidade escrita. Surdos deveriam ter acesso à escola desde os 0 anos, para adquirir uma língua, mas muitas escolas brasileiras não dispõem de professores que dominam a Libras. Algumas escolas utilizam o bimodalismo, emprego simultâneo da língua oral e da língua de sinais, o que reduz esta a mero recurso educacional, prejudicando seu desenvolvimento como língua de interação e instrução e, conformidade com o modelo bilíngue para surdos.

Um importante momento do movimento surdo foi a luta pela inserção da Educação Bilíngue para Surdos no "Plano Nacional de Educação para o decênio 2014/2024". O Plano Nacional de Educação (PNE) define metas e estratégias para políticas educacionais a serem executadas em um período de dez anos. A elaboração do plano é precedida pela Conferência Nacional de Educação (CONAE), que tem por objetivo elaborar e votar propostas para o PNE. Segundo as autoras surdas Campello e Rezende (2014), na CONAE de 2010 os representantes da comunidade surda defenderam onze propostas, visando a criação e a manutenção de escolas bilingues, dentre as quais apenas três foram aprovadas. As lideranças governistas, contrárias às propostas da comunidade surda, alegaram que a escola bilingue para surdos era segregacionista. A partir de então as escolas de surdos passaram a ser ameaçadas de fechamento. No dia 17 de março de 2011, a Diretora de Política de Educação Especial, Martinha Claret, foi ao Instituto Nacional de Educação de Surdos (INES) afirmar que o mesmo seria fechado até 2011 e os alunos surdos remanejados para escolas comuns. Um dos líderes do Movimento Surdo e professor efetivo do INES, Nelson Pimenta, gravou um vídeo alertando toda a comunidade surda que, em resposta, fez uma passeata histórica contra o fechamento das escolas de surdos, nos dias 19 e 20 de maio 


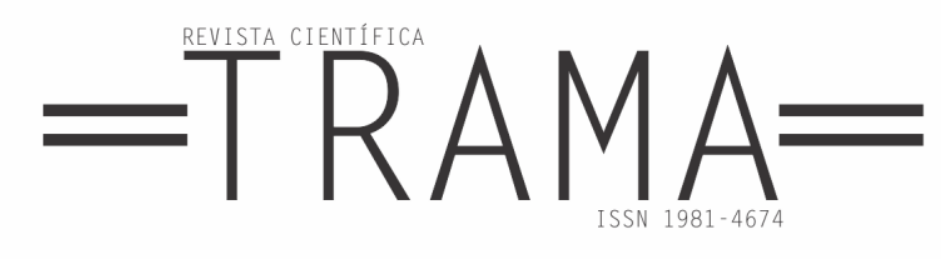

de 20114. Após o evento, os surdos ainda organizaram várias palestras em Defesa das Escolas Bilíngues para Surdos no PNE. (CAMPELLO, REZENDE, 2014).

A Revista da FENEIS publicou uma reportagem contra o fechamento do INES. Segundo a reportagem, escrita por Garcèz (2011), mais de quatro mil pessoas que foram à Brasília nos dias 19 e 20 de maio daquele ano se mobilizaram contra a proposta do MEC, que visava fechar escola de/para surdos e escolas especiais, e colocar os alunos surdos na escola inclusiva.

Campello e Rezende (2014) afirmam que a segregação ocorre na escola inclusiva, onde surdos e ouvintes não falam a mesma língua. Tendo isso em vista, no ano de 2012 o Movimento Surdo conseguiu que o Deputado Ângelo Vanhoni tramitasse na Câmara de Deputados a inclusão da Escola Bilíngue para Surdos no PNE. O texto proposto na Câmara dos Deputados, no entanto, foi alterado à revelia do Movimento Surdo ao passar no Senado. Na proposta do Movimento Surdo, na meta do PNE deveria constar que a oferta de ensino bilíngue para surdos seria feita em "escolas e classes bilíngues e em escolas inclusivas". No texto aprovado e alterado, à revelia do Movimento Surdo, no ano de 2013, permaneceu apenas "em escolas e classes bilíngues inclusivas", modificando o sentido da proposta do Movimento Surdo. Disso seguiu-se nova passeata em Brasília, no dia 14 de agosto de 2013. Após a passeata, o projeto seguiu para a tramitação na Câmara de Constituição, Justiça e Cidadania. O MEC exerceu influência para que fosse aprovado um texto que não garantiu a educação bilíngue para surdos. Na nova redação foi retirada a palavra "inclusiva", ficando da seguinte forma "em escolas e classes bilíngues". Com a alteração, abriu-se precedente para que a educação de surdos se desse em escolas comuns, onde a língua de instrução é oral, complementada por Atendimento Educacional Especializado (AEE) no contraturno. Tanto na escola inclusiva, quanto na classe inclusiva, a língua de instrução é oral, o que não propicia o pleno desenvolvimento dos surdos. Não é o que os surdos querem, mas sim a Educação Bilíngue de/para surdos, com instrução em Libras. Campello e Rezende (2014) citam os estudos de Capovilla, que comprovam a importância da língua de sinais para o desenvolvimento das pessoas surdas.

Capovilla (2008) coordenou, no período compreendido entre 1999 e 2009, o Programa de Avaliação Nacional do Desenvolvimento Escolar do Surdo Brasileiro (Pandesb), com objetivo de mapear o desenvolvimento cognitivo de crianças e adultos surdos. No estudo, mais de 8.000 surdos, de 15 estados brasileiros, foram submetidos a uma bateria de testes que tiveram o objetivo de mapear o desenvolvimento de competências cognitivas e linguísticas em leitura alfabética, leitura de textos, escrita alfabética, leitura orofacial e compreensão de sinais de Libras. Capovilla (2008) concluiu que a política de inclusão é benéfica para os deficientes auditivos, mas não para os surdos. O surdo, para o autor, se caracteriza por ter a língua de sinais como materna e se beneficia de escolas especificas com professores fluentes em língua de sinais, usada para ensinar a língua portuguesa e outros conteúdos.

Sobre o estudo de Capovilla, é importante ater-se à diferenciação que o autor estabelece entre "surdos" e "deficientes auditivos", uma vez que a inclusão é vista como benéfica para estes. O Instituto Brasileiro de Geografia e Estatística (IBGE), na pesquisa de amostra por domicílio para o censo de 2010 (IBGE, 2010), contabilizou 9.717.318 deficientes auditivos, classificados conforme segue:

- População com deficiência auditiva (não consegue de modo algum): 344.206 pessoas;

- População com grande dificuldade: 1.798.967;

- Alguma dificuldade: 7.574.145.

A população de 344.206 pessoas que não ouvem de modo algum equivale a apenas $3,6 \%$ do total de deficientes auditivos.

4 Disponível em: <encurtador.net/JV128>. Acesso em: 20 maio 2018. 


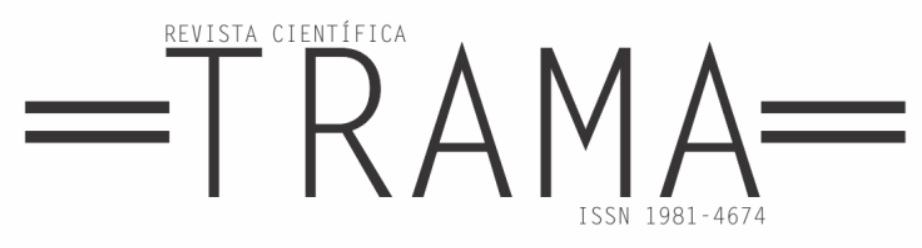

Detalhe importante é que toda a população é caracterizada como "deficiente auditivo". Nas estatísticas do IBGE não constam as palavras "surdo", "pessoa surda" ou "surdez", mas apenas "deficiente auditivo". Assim, tendo em vista que Capovilla defende a escola para surdos, e não para os deficientes auditivos, e, ainda, que 95\% das crianças surdas nascem em lares de ouvintes que não dominam a língua de sinais, correse o risco de que os argumentos de sua pesquisa sejam insuficientes para a defesa de escola de/para surdos. Para as pessoas caracterizadas como "deficientes auditivos", Capovilla afirma ser eficaz a escola inclusiva.

Sendo o surdo caracterizado como pessoa que tem a língua de sinais como materna, é preciso questionar se não é possível que crianças surdas, cujas famílias optem por tentar a oralização e o uso de aparelhos e próteses auditivas, acabem por sequer serem matriculadas em escolas de surdos. Na educação bilingue para surdos, conforme o modelo adotado na Suécia e explicitado por Svartholm (2014), a criança surda ou com deficiência auditiva tem acesso ao ensino da língua de sinais em escolas de educação infantil logo nos primeiros meses de vida, mesmo podendo vir posteriormente a usar aparelho ou prótese auditiva. A razão para isso é que a criança necessita, para o desenvolvimento cognitivo, de acesso a uma língua desde os primeiros dias de vida, quanto ainda não é possível o uso de aparelhos ou próteses auditivas.

Em 2008 o MEC tentou classificar a educação de surdos como "especial", no documento Política Nacional de Educação Especial na Perspectiva da Educação Inclusiva (BRASIL, MEC, 2008). $\mathrm{Na}$ educação especial o surdo estuda em escola inclusiva e recebe, no contraturno da aula, Atendimento Educação Especializado (AEE). Segundo Lodi (2013), inserir a educação de surdos na educação especial é incompatível com a perspectiva bilíngue, para a qual a surdez não é deficiência, mas sim diferença. A Libras não é a língua de instrução na educação especial, razão pela qual o Movimento Surdo também não aceita o modelo de educação especial.
O Plano Nacional de Educação foi aprovado em 2014, sob a forma de Lei ${ }^{\circ}$ 13.005 que institui o Plano Nacional de Educação para o Decênio 2014/2024, com a seguinte redação:

4.7. garantir a oferta de educação bilíngue, em Língua Brasileira de Sinais (Libras) como primeira língua e na modalidade escrita da língua portuguesa como segunda língua, aos(às) alunos(as) surdos e com deficiência auditiva de zero a dezessete anos, em escolas e classes bilíngues e em escolas inclusivas, nos termos do art. 22 do Decreto $\mathrm{n}^{\circ} 5.626$, de 22 de dezembro de 2005, e dos arts. 24 e 30 da Convenção sobre os Direitos das Pessoas com Deficiência, bem como a adoção do sistema braile de leitura para cegos e surdos-cegos; (BRASIL, 2014).

A redação da lei permite a interpretação de que a educação bilíngue pode ocorrer tanto em escolas e classes bilíngues, quanto em escolas inclusivas. Embora a lei não implique no automático fechamento das escolas de/para surdos, também não garante a permanência das mesmas, uma vez que permite a coexistência com as escolas inclusivas. Portanto, o movimento Surdo terá de continuar lutando para que as escolas de/para surdos não sejam fechadas.

A história do Movimento Surdo demonstra que os surdos não apenas precisam lutar para aprovar leis, mas também para que estas sejam cumpridas. Isso é o que mostra o relato da professora coautora deste trabalho. A professora nasceu em São Paulo, onde completou o ensino fundamental em escola regular (de ouvintes), sem acompanhamento de Tradutor e Intérprete de Libras (TILS). Filha de pai paraguaio e mãe brasileira, foi oralizada em tratamento fonoaudiológico e psicopedagógico. No ano de $2003 \mathrm{fez}$ magistério em uma escola estadual de Foz do Iguaçu e, depois, cursou duas faculdades, uma de Pedagogia e outra de Letras/Libras.

Como sou professora de Libras, trabalhava como apoio educacional. Vi sofrimentos e reclamações dos alunos surdos na escola regular. Lembrava o que havia passado na minha infância. 


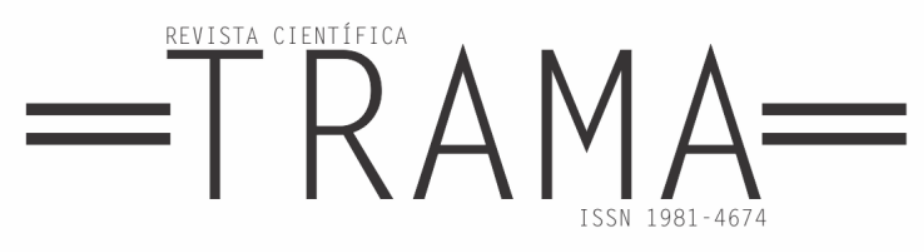

Como sou surda, estudei numa escola inclusiva, isto é, escola regular, mas sem intérprete de Libras. Difícil ter amigos, era época de oralismo, usava aparelho auditivo, tentava ler os lábios dos professores, mas nada adiantava, pois falavam rápido, viravam de costas, colocavam papel na frente dos lábios, andavam enquanto explicavam o conteúdo. Foi difícil pegar conteúdo e nem conseguia aprender durante aulas. Só aprendi a ler e a escrever. Mas não sabia o sentido das palavras. Ia para a fonoaudióloga aprender a falar e a ouvir, mas mesmo assim não conseguia entender o sentido das palavras. Não era feliz na vida, foi muito pesado, não tinha infância boa, só brincava nos fins de semana. Durante semana ia a médico, fonoaudióloga, professora particular e escola. Não aprendi Libras, que era proibido, tinha conhecimento limitado. É mesma coisa que acontece com crianças surdas que estudam na escola regular sem intérprete. Fica difícil situação, se torna aluno terrível, pois falta comunicação. Lembro-me um meu amigo surdo que contou que ficava na sala de aula, com ouvinte falando muito, professores falando e ele nem sabia o que estavam falando e qual era o conteúdo. Dormia, dormia, dormia toda aula, reprovou muito. E hoje, já adulto, é professor de Libras, formado em faculdade, mas sente triste $o$ passado. Os professores nem se preocupavam com ele. Eu estive na passeata em Brasília em 2011. Conheci uma surda de nove anos de idade que falou "na escola de ouvinte não temos com quem conversar. Na escola de surdos é mais fácil. Se surdo não se comunicar, nós ensinamos Libras para ele e ele se desenvolve. Em escola onde professor só fala, como vamos entender ele? Somos surdos!" Isso é muito comum na maioria das escolas que não têm intérprete de Libras. Desde educação infantil, até ensino médio e faculdade particular, estudei sem intérprete de Libras.

Com a presença de Intérprete de Libras as coisas melhoraram, mas ainda tem problema. Pela primeira vez na minha vida, quando estudei no magistério, teve presença de quatro surdos e intérprete de Libras. Comecei a aprender Libras, conhecer a comunidade surda, sua língua e sua cultura. Senti mais leve de entender conteúdo, mas deu um trabalhão. Meus olhos se cansam, olhando para Intérprete e Tradutor Língua de Sinais (TILS). Ao mesmo tempo olhava para quadro negro $e$ livro. Eu não tenho uns seis olhos para olhar tudo durante aula, cansa. Ainda professor fala rápido, TILS precisa conhecer o conteúdo para sinalizar, mas nem tudo tem sinal de tal conteúdo. É preciso estudar tal conceito para criar sinal de tal vocabulário e ainda não tem tudo. Também falta recurso visual, filme legendado, mas a maioria dos professores esquece, e tenho que ver ao mesmo tempo. Precisa ter TILS e material didático dinâmico para que alunos surdos e ouvinte possam aprender melhor os conteúdos. Ainda é difícil para TILS e para professores explicar conteúdo, pois são conceitos abstratos e precisa explicar claro. Exemplo, falar da célula, glóbulos vermelhos, surdo não tem noção sobre o que é isso. Mostrando visual, como funciona o que é. $O$ surdo até pode compreender e criar sinal de célula $e$ glóbulos vermelhos. Cada área não tem pronto específica de Libras, ainda faltam muitos materiais e dicionários de Libras. E também cabe a formação de TILS. Antes do decreto de Libras, não tinha faculdade bacharelado de Letras Libras. Os TILS tiveram de fazer vários cursos específicos para esta formação. Os meus alunos relataram que atualmente, com a política de inclusão, não valorizam muito o trabalho dos TILS. Aqui no Paraná, governo paga pouco para TILS e falta 4 horas para completar, e com isso TILS não vai trabalhar, pois 'folga' e alunos ficam sem TILS. Com isso, prejudica a aprendizagem. Somente em 2012 conseguiram TILS para horário de 'folga', ou seja, substituto, mas mesmo assim tem problema, por causa da combinação de sinal de tal conteúdo. Pela primeira vez no Brasil, após aprovar a Lei de Libras e o Decreto de Libras, no ano 2006, a Universidade Federal de Santa Catarina (UFSC) abriu curso Licenciatura de Letras Libras, para formação de professor de Libras em 9 pólos, escolhi Florianópolis. Por quatro anos de estudos, me senti tão feliz na vida, pois curso é ministrado por professores surdos com mestrado e doutorado, $e$ 


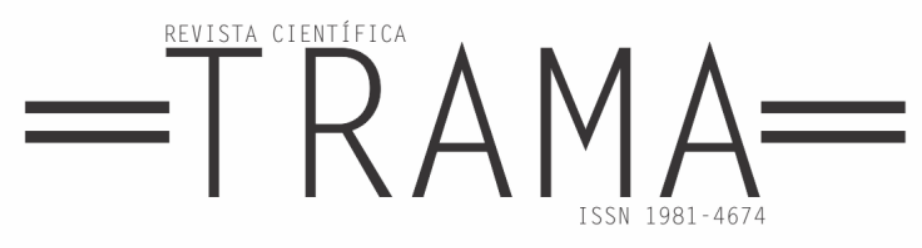

professores ouvintes com presença de TILS, usando recurso visual $e$ adaptando de acordo com a cultura surda, e os acadêmicos são surdos. Senti que estava no mundo dos surdos. Aprendi com rapidez. Compartilhamos experiência de trabalho escolar, trocamos dúvida e conhecimento da área. É um curso bilíngue, na qual a primeira língua usada é Libras e o português é na modalidade escrita. E com isso, desenvolvemos a cultura surda, valorizando variações linguísticas e concepção política. Nós surdos queremos este modelo para toda escola bilingue de/para surdos.

Avançamos mais o conhecimento $e$ queremos que estudo seja "eterno". Por isso, nós surdos queremos educação bilíngue, pois aprende mais e melhor por causa de comunicação que é Libras. Capovilla ${ }^{5}$ defende escola bilíngue porque a criança surda desenvolve melhor devido a interação com professores e colegas sinalizadores. Por isso, a escola bilíngue é fundamental para criança surda brasileira. Ele comprovou uma pesquisa que a criança que estuda na escola bilíngue aprende mais e são melhores do que a criança que surda que estuda na escola inclusiva. O estudo comprova que o apoio pedagógico fora do horário de aula não substitui a educação bilíngue de qualidade, pois tem profissionais que são fluentes em Libras. (Relato da autora surda deste trabalho. Novembro de 2017).

A confusão terminológica entre "educação bilingue de/para surdos", "inclusão de surdos" e "educação especial para surdos" afeta diretamente a vida de seres humanos, podendo provocar a permanência dos sofrimentos de uma comunidade já historicamente privada de sua cultura e de sua língua.

O Ministério da Educação, por meio da Secretaria de Alfabetização Continuada, Alfabetização, Diversidade e Inclusão (SECADI), designou um grupo de trabalho para elaborar políticas de educação para surdos, nomeado pela Portaria $\mathrm{N}^{\circ}$ 1.060/2013, e $\mathrm{N}^{\mathrm{o}} 91 / 2013$. O grupo produziu um documento com recomendações de políticas para educação de surdos, intitulado "Relatório sobre a Política Linguística de Educação Bilíngue - Língua Brasileira de Sinais e Língua Portuguesa" (MEC/SECADI, 2014). O documento demostra o quanto a compreensão de educação bilingue para surdos tem interpretações diversas e contraditórias. Cita a caracterização de escola bilingue, elaborada em 2013 pela Federação Nacional de Educação e Integração dos Surdos (FENEIS):

[...] a FENEIS (2013) caracteriza as escolas bilíngues da seguinte forma: As escolas bilíngues são aquelas onde a língua de instrução é a Libras e a Língua Portuguesa é ensinada como segunda língua, após a aquisição da primeira língua; essas escolas se instalam em espaços arquitetônicos próprios e nelas devem atuar professores bilíngues, sem mediação de intérpretes na relação professor - aluno e sem a utilização do português sinalizado (MEC/SECADI, 2014, p. 04).

No entanto, apesar de citar a caracterização da FENEIS, define, nas recomendações finais, a escola bilingue de modo a abrir precedente para a inclusão:

2. Garantir a educação bilíngue de surdos em classes bilíngues em escolas inclusivas (que não são escolas bilíngues de surdos) de ensino comum em municípios que baixa demanda de surdos, quando não houver escolas polos multimunicipais na região.

3. Garantir o ensino da Libras e da Língua Portuguesa como L2 M2 na educação de surdos matriculados em escolas comuns, com a presença de intérpretes de Libras e Língua Portuguesa, professores de Libras prioritariamente surdos, e professores de Língua Portuguesa como L2, quando não houver como agrupar surdos. (MEC/SECADI. 2014, p. 20).

Trata-se, portanto, de mais um precedente para a não manutenção das escolas bilíngues de/para surdos. A mesma luta para manter a proposta bilíngue é

\footnotetext{
${ }^{5}$ Citado em Garcèz (2011).
} 


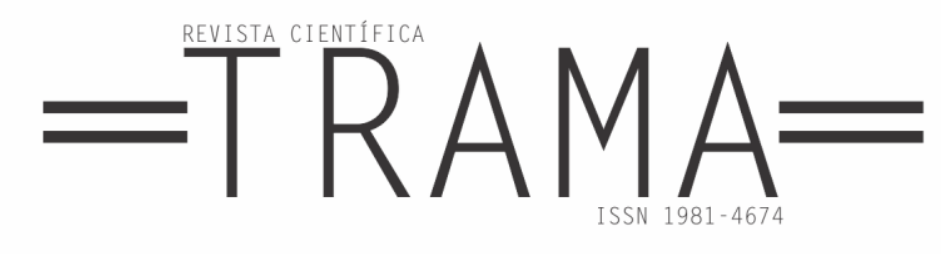

verificada nos estados, como ocorre no Paraná.

\section{Movimento surdo no paraná E EM FOZ DO IGUAÇU}

A Libras foi reconhecida no Estado do Paraná em 1998, quando foi publicada no Diário Oficial a Lei $\mathrm{n}^{\circ} 12.095$, de 11 de março de 1998. Na época os surdos estudavam em escolas especiais e eram tratados como doentes e casos clínicos, e não como cidadãos. A visão clínico-terapêutica, que pautava as escolas especiais, acarretava na busca pela "reabilitação" da audição e da fala.

O direito à Libras nos serviços públicos e nas escolas públicas e privadas onde estudassem surdos somente foi reconhecido no estado do Paraná sete anos depois, com ajuda do Decreto Federal no $5.626 / 2005$, que regulamentou o direito à língua de sinais. Ainda quatro anos depois, em 2009, o Movimento Surdo precisou se mobilizar para garantir o acesso à Libras no Paraná. Segundo reportagem de Yano e Angeli (2009), no Jornal paranaense Gazeta do Povo, a comunidade surda de todo o Paraná se mobilizou em Curitiba, no dia 01 de Junho de 2009, pela defesa de direitos na educação, como o cumprimento da obrigatoriedade da Libras nas escolas, serviços públicos e em empresas privadas em Libras, de acordo com o Decreto Federal no 5.626 de 2005.

Entre as principais reivindicações do grupo estão a contratação imediata de professores surdos e intérpretes da Língua Brasileira de Sinais (Libras) para atuarem em todas as escolas do estado; o ensino de Libras nos cursos de formação de professores, em universidade públicas e privadas; além do ensino de Libras nas escolas onde estudam alunos surdos. Segundo Iraci Suzin, diretora administrativa da Feneis-PR, o protesto é pacífico. "Estamos apenas pedindo o cumprimento de determinações que já estão previstas em lei" (YANO, ANGELI, 2009, grifos dos autores).

Segundo a reportagem, com o reconhecimento oficial da Libras, novas demandas para a educação de surdos no Paraná foram exigidas. A reportagem afirma que a Secretaria de Estado da Educação (SEED) apoia e diz: "Entendemos a importância da educação bilíngüe. O Estado está mantendo as escolas para surdos, fazendo a inclusão deles nas escolas regulares e investindo na formação de tradutores e intérpretes de Libras" (YANO e ANGELI, 2009).

No ano de 2016, nova luta foi necessária, quando a educação de surdos no Paraná foi inserida como educação especial, na Deliberação No 02/2016, que "Dispõe sobre as Normas para a Modalidade Educação Especial no Sistema Estadual de Ensino do Paraná". No parágrafo sétimo do artigo 13, a Lei afirma que a oferta de educação bilíngue para estudantes surdos deverá ocorrer no âmbito do Atendimento Educacional Especializado (AEE), precedente este aberto pelo PNE, Lei $n^{\circ} 13.005 / 2014$.

Na cidade de Foz do Iguaçu, a Luta do Movimento Surdo garantiu a fundação e vem garantindo a permanência de uma escola bilíngue para surdos, a Escola Lucas Silveira para Surdos da Associação de Pais e Amigos dos Surdos de Foz do Iguaçu (APASFI). A APASFI foi fundada em 08 de dezembro de 1982. A escola mantida pela APASFI foi fundada em 19 de Setembro de 1999. Segundo Fernando (2015), a escola oferece ensino seriado regular para educação infantil até o quinto ano do ensino fundamental para alunos surdos. Além disso, oferece reforço escolar no contraturno para alunos surdos de toda a educação básica. Trata-se de uma escola bilíngue para surdos, onde Libras é a língua de instrução, tanto que toda a equipe de pessoas que trabalham na escola domina a Libras.

A primeira lei de acesso a Libras em Foz do Iguaçu foi aprovada em 19 de Dezembro de 1996. Trata-se da Lei Municipal no 2.055, que estabelece, em seu artigo primeiro: "Fica reconhecida oficialmente, pelo Município de Foz do Iguaçu, a linguagem gestual codificada na Língua Brasileira de Sinais LIBRAS - e outros recursos de expressão a ela associados, como meio de comunicação objetiva e de uso corrente." Segundo relato da autora surda deste artigo: 


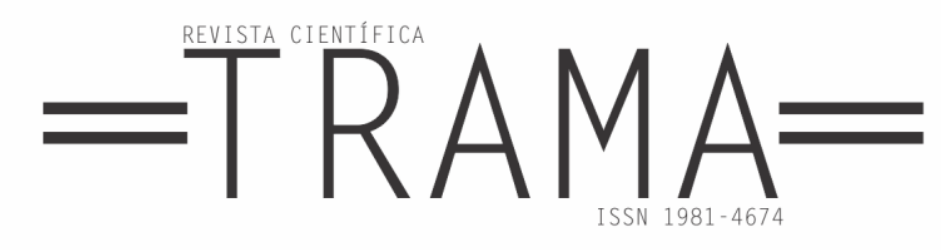

Nesta época, a Associação de Pais e Amigos dos Surdos Foz do Iguaçu (APASFI) proporcionava ensino oralizado, mesmo a lei já tendo sido aprovada. Em 1998, dois anos depois da lei municipal ser publicada, professores e crianças surdas foram para a Câmara Municipal reivindicar acesso à Libras. Na época um vereador mostrou a lei e todos ficaram surpresos. $\mathrm{Na}$ escola, diretora e professores entraram conflito, mas no início nada mudou. $O$ ensino continuou sendo oralista. Os surdos adultos, por volta no ano de 2002, foram ao campeonato dos surdos do Paraná, em Maringá, e perceberam que existiam vários surdos falando em Libras e ficaram surpresos com isso. Desta forma, começaram a aprender como eles. Quando voltaram para Foz do Iguaçu, houve uma revolta: professores surdos defendiam a Libras $e$ alguns professores ouvinte não. Mas finalmente ficou decidido. A turma de manhã e da tarde continuaria no ambiente do oralismo e, os alunos do período da noite, eram livres para usar a Libras. Foi um momento de liberdade, mas poucos surdos conheciam Libras. Então foi escolhido um surdo para fazer curso de Libras em Curitiba. Posteriormente o mesmo aluno foi para Brasília, num esforço do MEC, e foi aprovado como um dos melhores agente multiplicadores de Libras no Brasil. Quando voltou para Foz do Iguaçu começou a ensinar a Libras para surdos adultos e houve uma evolução muito grande; ao mesmo tempo, foi aprovado o uso da Libras pela APASFI em todas as idades e períodos. E com isso houve avanços para a Comunidade Surda de Foz do Iguaçu. No ano de 2003, houve duas lutas conquistadas pela Comunidade Surda: num Colégio que tem curso de magistério, quatro surdos ingressaram como alunos mas não havia acessibilidade, isto é, Intérprete de Libras. A diretora e a coordenação do curso de Magistério, em conjunto com a APASFI, conseguiram contratar um Intérprete de Libras. Foi a primeira escola a ter Intérprete de Libras no Paraná. E a outra conquista foi o concurso público para professores municipais, uma jovem foi a primeira professora surda a passar em concurso público em Foz do Iguaçu. (Relato da autora surda deste trabalho. Novembro de 2017).

Os relatos da autora surda deste artigo mostram que em cada município e em cada escola é preciso lutar, não apenas para que leis de acesso a língua de sinais sejam efetivadas e para que a pessoa surda tenha acesso à educação, saúde e convivência de acordo com suas necessidades, mas, também, pela Educação Bilíngue de/para Surdos.

\section{Considerações finais}

Os surdos precisam ter acesso à Língua de Sinais de uma comunidade logo que nascem. Disso deriva a importância de que a escolaridade do surdo comece aos 0 anos de idade, como ocorre na Suécia. Se isso não ocorrer, a família que não domina a língua de sinais poderá até inventar um jeito de se comunicar com a criança, mas isso não the permitirá a apropriação de conceitos mais científicos e nem a participação em uma comunidade linguística maior.

Com isso, a luta da comunidade surda por acessibilidade, educação e direito à Língua de Sinais, foi importante no Brasil para que a Libras fosse normatizada em Leis em Decretos. Mas mesmo quando estas leis e decretos são aprovados, não há garantia de efetivação. Por isso a luta precisa continuar, em cada município e em cada escola, como demonstra a experiência da professora surda autora deste artigo. Importa dizer que surdos querem a escola bilíngue de/para surdos, pois precisam ter a língua de sinais como língua de instrução, o que não acontece no modelo inclusivo e nem no AEE. Para que surdos não sejam segregados, precisam de instrução em língua de sinais e convivência com outras pessoas surdas, desde o nascimento. 


\section{$=$ TRAMA $=$}

\section{$\mathbf{R}_{\text {EFERÊNCIAS }}$}

BRASIL. Decreto $\mathrm{N}^{\circ} \mathbf{5 . 6 2 6}$ de 22 de Dezembro de 2005. Regulamenta a Lei $\mathrm{N}^{\circ}$ 10.436, de 24 de Abril de 2002, que dispõe sobre a Língua Brasileira de Sinais - Libras, e o art. 18 da Lei $\mathrm{N}^{\circ} 10.098$, de 19 de Dezembro de 2000. Disponível em: <encurtador.net/hARSY>. Acesso em: 26 nov. 2017.

BRASIL. Ministério da Educação. Secretaria de Educação Especial. Política Nacional de Educação Especial na Perspectiva da Educação Inclusiva. Brasília, 2008. Disponível em: <http://portal.mec.gov.br/arquivos/pdf/politicae ducespecial.pdf $>$. Acesso em: 12 abr. 2012.

BRASIL. Ministério da Educação (MEC). Secretaria de Alfabetização Continuada, Alfabetização, Diversidade e Inclusão (SECADI). Relatório sobre a Política Linguística da Educação Bilingue Língua Brasileira de Sinais e Língua Portuguesa. Grupo de Trabalho designado pelas portarias $\mathrm{n}^{\circ} 1.060$ de $2013 \mathrm{e} \mathrm{N}^{\circ}$ 91/2013 do MEC/SECADI. Brasília, 2014.

BRASIL. Plano Nacional de Educação 2014/2014, Lei $\mathrm{N}^{\circ} 13.005$, de 25 de Junho de 2014 que aprova o Plano Nacional de Educação (PNE) e dá outras providências. Disponível em: <http://www.observatoriodopne.org.br/uplo ads/reference/file/439/documento-

referencia.pdf>. Acesso em 27 nov. 2017.

CAMPELLO, Ana Regina. REZENDE, Patrícia Luiza Ferreira. Em Defesa da Escola Bilingue para Surdos: a História de Lutas do Movimento Surdo Brasileiro. Educar em Revista. Curitiba, Paraná. N. 2, p. 71-92, 2014. Disponível

http://www.scielo.br/pdf/er/nspe-2/06.pdf.

Acesso em: 19 dez. 2017.

CAPOVILLA, Fernando C. Filosofias Educacionais em Relação ao Surdo: do Oralismo à Comunicação Total ao Bilinguismo. Revista Brasileira de
Educação Especial. v. 6, n. 1, p. 99-116. 2000.

CAPOVILLA, F.C. Principais achados e implicações do maior programa do mundo em avaliação do desenvolvimento de competências linguísticas de surdos. In: SENNYEY, A; CAPOVILLA, F. C; MONTIEL, J.M F. (Orgs). Transtornos de aprendizagem. São Paulo, SP: Artes Médicas, 2008, p. 151-164

CICCONE, Mário. Comunicação Total. Rio de Janeiro: Cultura Médica, 1990

Estado do Paraná. Lei 12.095, de 11 de Março de 1998. Reconhece Oficialmente, pelo Estado do Paraná, a Linguagem Gestual Codificada na Língua Brasileira de Sinais. Disponível em: <http://www.legislacao.pr.gov.br/legislacao /pesquisarAto.do?action=exibir\&codAto $=2$ 626\&codItemAto $=17854>$ Acesso em $19 / 12 / 2017$

Estado do Paraná. Conselho Estadual de Educação. Dispõe sobre as Normas para a Modalidade Educação Especial no Sistema Estadual de Ensino do Paraná. Curitiba, Setembro de 2016. Disponível em: <http://www.cee.pr.gov.br/arquivos/File/pd f/Deliberacoes/2016/Del_02_16.pdf>.

Acesso em: 19 dez. 2017.

FENEIS. Federação Nacional de Educação e Integração dos Surdos. A educação que nós surdos queremos. Documento elaborado pela comunidade surda a partir do précongresso ao V Congresso latino-americano de Educação Bilíngue para Surdos, realizado em Porto Alegre/RS, no salão de atos da reitoria da UFRGS, nos dias 20 a 24 de abril de 1999.

FERNANDES, Sueli. MOREIRA, Laura Ceretta. Políticas de Educação Bilíngue para Surdos: o Contexto Brasileiro. Educar em Revista. Paraná: Curitiba, Edição Especial, n. 2, p. 51-69, 2014. Disponível em: <encurtador.net/eyELY>. Acesso em: 29 nov. 2017. 


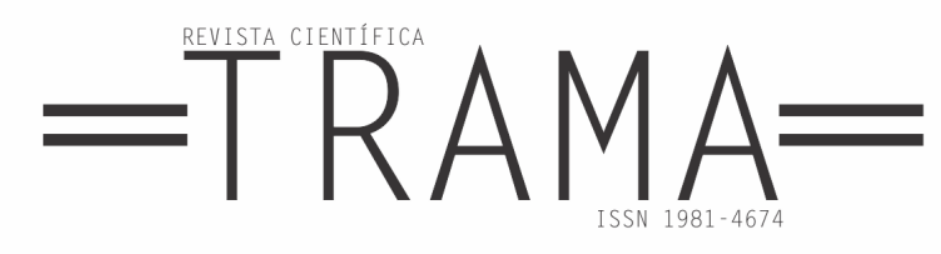

FERNANDO, Odete Agostinho. Investigação sobre Materiais Manipuláveis e Jogos de Matemática Utilizados por Professores no Ensino de Crianças Surdas nos Anos Iniciais. Dissertação (Mestrado). Foz do Iguaçu: Programa de Pós-Graduação Stricto Sensu em Ensino, Nível Mestrado, 135 p, 2015.

FOZ do Iguaçu. Lei $\mathbf{N}^{0} 2055$ de 19 de Dezembro de 1996. Reconhece oficialmente, no município de Foz do Iguaçu, como meio de comunicação objetiva e de uso corrente, a Linguagem Gestual Codificada na Língua Brasileira de Sinais, LIBRAS. Disponível em: <encurtador.net/lmtw6>. Acesso em: 10 dez. 2017.

GARCÈZ, Regiane Lucas. Nada sobre nós, sem nós. Um ato político e Cultural. Revista da FENEIS. No 44, Junho-Agosto de 2011. p. $8-15$

HONORA, Márcia. Inclusão Educacional dos Alunos com Surdez: concepções e alfabetização. São Paulo: Cortez, 2014

Instituto Brasileiro de Geografia e Estatística (IBGE). Censo Demográfico 2010. Características Gerais da População, Religião e Pessoas com Deficiência. Disponível em: <https://biblioteca.ibge.gov.br/visualizacao/ periodicos/94/cd_2010_religiao_deficiencia .pdf>. Acesso em: 13 maio 2018.

LODI, Ana Cláudia Balieiro. Educação Bilingue para Surdos e Inclusão segundo a Política Nacional de Educação Especial e o Decreto $N^{\circ}$ 5626/05. Educação e Pesquisa. São Paulo. V. 39, N. 01, p. 49-63, 2013.

Organização das Nações Unidas para a Educação, a Ciência e a Cultura (UNESCO). Declaração Universal dos Direitos Linguísticos. UNESCO, 1996. Disponível em:

<http://www.dhnet.org.br/direitos/deconu/a _pdf/dec_universal_

direitos_linguisticos.pdf> Acesso em: 22 maio 2018.
QUADROS, Ronice Müller de. CRUZ, Carina Rebello. Língua de Sinais. Instrumento de Avaliação. Porto Alegre: ARTMED, 2011.

QUADROS, Ronice Müller de. SCHMIEDT, Magali, L.P. Idéias para Ensinar Português para Alunos Surdos. 120 p. Brasília, Ministério da Educação (MEC), Secretaria de Educação Especial (SEESP), 2006

STOKOE, W.C. Sign Language Structure. An outiline of the visual communication system for the American Deaf. Buffalo: Buffalo University, 1960.

SVARTHOLM, Kristina. Bilinguismo dos Surdos. In. SKLIAR, Carlos. Atualidade da Educação Bilingue para Surdos. Interfaces entre Pedagogia e Linguística. Porto Alegre: Mediação, 2009, p. 15-23.

SVARTHOLM, Kristina. 35 anos de educação bilingue de surdos - e então? Educar em Revista. Curitiba, Brasil: Editora UFPR, Edição Especial, n. 02, p. 33$50,2014$.

YANO, Célio. ANGELI, Gladson. Surdos fazem passeata em Curitiba em defesa de Direitos na Educação. Curitiba, Paraná: Gazeta do Povo. 01 de Junho de 2009. Disponível em: <encurtador.net/ijpQ6> Acesso em: 10 dez. 2017. 